\title{
Central bank's supervision on commercial banks' credit business an exploratory post-epidemic-based research
}

\author{
LI Tingen ${ }^{1, \mathrm{a}}$, FANG Huan*1,b ${ }^{\text {ZHANG Yanting }}{ }^{1, \mathrm{c}}$ \\ ${ }^{1}$ Guangzhou College of Technology and Business, Foshan, Chinese
}

\begin{abstract}
The epidemic of COVID-19 broke out, domestic economy suffered a heavy setback, the Central Bank of China launched a series of policies against this backdrop, aiming to stimulate the economy. However, some investors speculate from the loose loans in real estate, which makes the funds policy originally used for stimulating the real economy to be artificially drained into the real estate market, further resulting in the imbalance of social supply. To solve this problem, from the perspective of the central bank and with the use of literature research and other methods, this paper makes research on analyzes the central bank's credit supervision on commercial banks. Study shows that information collection and monetary policy are the problems with central bank. Through big data technology and monetary policy into the new reference index two angles to try to solve the problem. It aims to effectively strengthen the efficiency and level of central bank's supervision. Meanwhile it can provide corresponding theories and references for subsequent research. The limitation of this study is that there is no specific application supporting the analysis. Otherwise the paper would be more applicable in practice. Therefore, this problem needs to be further studied and solved.
\end{abstract}

\section{INTRODCUTION}

\section{A. Research background}

According to China economic data of the year 2020 released by State Statistical Bureau, China's GDP in the first quarter is 20605.4 billion yuan, a year-on-year decrease of $6.8 \%$. From January to April, profits of industrial enterprises above the designated size totaled 1259.79 billion yuan, a year-on-year decrease of $27.4 \%{ }^{[33]}$. In view of the hit that China's economy and the small and medium-sized enterprises suffered from the epidemic, central bank has given targeted support to the key areas and enterprises of epidemic prevention and control, and small \& medium-sized as well as micro enterprises and private enterprises by reducing the deposit reserve ratio, opening market business and promoting further credit support. And the credit support to small, medium and micro enterprises and private enterprises is put emphasis on [34]. With central bank's strong credit support, according to State Statistical Bureau, the stock of social financing scale at the end of May is 268.39 trillion yuan, a year-on-year increase of $12.5 \%$; loans to the real economy increased by $13.3 \%{ }^{[35]}$. The rapid expansion of financing scale indicates the rapid growth of commercial bank's credit volume, and the main purpose for promoting credit scale is to make funds flow to real economy.
At the same time, loose monetary policy will also lead to a series of social problems. The research of scholars (Guo, Lu, Guo, Yan, Meng, 2009) shows that, with the law of market economy, funds used to support real economy and benefit the people's livelihood quickly flowed into stock market and real estate market, which is likely to cause asset prices to re inflate. As a result, loose monetary policy has promoted asset prices ${ }^{[20]}$. With central bank's loose monetary policy, the real estate market continues to rise, and social polarization are getting serious. The credit funds of commercial banks cannot be accurately provided to the groups in urgent need of funds, but flow to people with surplus funds. This phenomenon results in the imbalance of social supply and demand, and obvious structural problems with bank credit. Thus, how to direct funds to the real economy, it is of particular importance for China's economic development after being hit hard by the epidemic.

\section{B. Value of the research}

Study value of central bank's supervision on credit business of commercial banks has two aspects.

From theoretical aspect, previous studies on financial supervision mainly focus on policy and mechanism of central bank, on the basis of which, then analysis is done to the credit supervision of commercial banks. The existing research results for 2008 financial crisis era, are

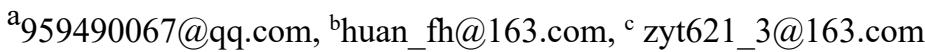


based on faced with inflation risk, bad assets risk and bubble risk in the implementation from the perspective of central bank instead of credit supervision of commercial banks. Furthermore, 2008 financial crisis era is quite different from the post-epidemic era in terms of regulatory policies and economic environment, therefore, the research results more or less may have the limitation of timeliness. However, the existing research results for the epidemic era mainly focus on financial regulatory policies from multiple perspectives, but not attach importance to the perspective of the central bank. Therefore, to carry out this research on the basis of previous research results, to a certain extent, it fills in the research gap of central bank's credit supervision on commercial banks, promotes the understanding of the importance of central bank supervision on the stable development of financial market, and updates the significance of central bank's supervision on the credit business of commercial banks. From a practical perspective, to analyze central bank's supervision over the credit business of commercial banks, to study a series of measures taken by the central bank in view of economic downturn, it can correctly guide the liquidity funds to flow to the real economy, infiltrating the real economy, and effectively prevent the economic bubble from growing, so that the economy can be effectively stimulated and develop steadily. In the era of world-wide economic downturn, to study on how the central bank takes the measures such as monetary policy to effectively stimulate China's economic development, it has a practical significance for reference.

\section{Methods}

The study of this paper is mainly based on the methods of literature research, exploratory research and qualitative analysis. First of all, literature is collected from CNKI, Wanfang database, library books and other materials so as to conclude research perspective and research results of the supervision of the central bank and the credit business of commercial banks, which has a theoretical conduciveness to the study of the paper. Then, qualitative analysis is used to summarize the literature and data collected, demonstrate the relationship between the central bank supervision and the credit business of commercial banks, and further explore the law of their correlation, which provides convincing references for the following exploratory research. Finally, on the basis of the existing data, an exploratory research is done to the central bank's supervision on the credit business of commercial banks so as to clarify the problems existing in central bank's supervision with more accuracy, and have a more comprehensive understanding of the research.

\section{LITERATURE REVIEW}

\section{A. Foreign literatures}

From the perspective of monetary policy (Bernanke \& Blinder, 1988), studies show that the regulation of money supply by monetary policy can affect commercial banks on their credit strategy, further affect the development of the real economy and productive speculation ${ }^{[8]}$. This is the early research results. Monetary policy, as a means of central bank's credit supervision on commercial banks, can realize the allocation of social funds through monetary policy.

\section{B. Domestic literatures}

Many domestic scholars have elaborated their own views on the supervision of the central bank mainly from several different aspects. From a functional point of view (Yin, 2011), studies show that after the global financial crisis, countries and regions in Europe, the United States and the United Kingdom have given the central bank macro prudential supervision function in the financial supervision reform, and it is believed that China should also strengthen macro prudential management function of the central bank, so as to improve the efficiency of financial supervision and maintain the stability of the financial system ${ }^{[3]}$. Macro Prudent is a kind of supervision measure for the purpose of maintaining the stability of the financial system and preventing the financial system from eroding the real economy. To strengthen macro prudential supervision of the central bank, it can not only reduce the possibility of systemic risk caused by financial crisis, but also relieve the spillover effect of financial system on the real economy. From the perspective of monetary policy (Wei, Jiang, Pang, 2012), according to studies, monetary policy has a significant impact on bank credit behavior, and tight monetary policy can effectively restrain bank credit expansion ${ }^{[4]}$. The tightening and looseness of monetary policy will affect the credit scale, thus indirectly controlling money supply and further achieving supervising purpose of the stability of financial market. From the perspective of regulatory talents and facilities (Cao, Shi, Zhang, 2014), on the basis of studies, construction of central bank supervision team is believed to be strengthened for coordinated development of financial supervision, with focus on the construction of regulatory information infrastructure and the cultivation of compound regulatory talents [1]. Regulatory information infrastructure and regulatory talents are the hard power for the central bank to guarantee the supervision efficiency. In addition, with the application and development of big data technology in China, processing capacity of data information is getting more improved, which can effectively promote the ability of regulatory measures in decision-making.

Many domestic scholars have set forth their own views on the existing domestic research on the credit business of commercial banks. From the perspective of credit risk (Cui, 2020), it is believed that the supervision and management environment of credit risk of commercial banks is constantly changing. Therefore, to better supervise and manage credit risk, it is necessary to constantly improve and perfect the supervision and management policies of credit risk of commercial banks, and carry out a comprehensive analysis on the credit status of users ${ }^{[6]}$. Commercial banks need to analyze users' credit status from multiple perspectives so as to reduce credit risk, while the central bank's credit management center can help commercial banks analyze users' credit. From the perspective of credit fund 
management (Zhang, 2004), studies show that the central bank should first strengthen the deposit cost constraints of commercial banks, strengthening the management and monitoring of credit funds of commercial banks, so that the monetary policy of the central bank can effectively affect the cost of bank credit funds. Secondly, the central bank should regulate commercial banks for the use of credit funds, ensuring that credit funds flow into the production field, and providing solid financial support for project financing and economic development [5]. Regulation on the scale of credit funds is realized indirectly by the central bank's monetary policy and other measures, therefore, the central bank's control is the key point for the credit funds to flow into the real economy.

In conclusion, the existing paper studies on the supervision of the central bank mainly concentrate on monetary policy, the quality of regulatory personnel, macro prudential function and credit management. While the research on the credit business of commercial banks mainly focus on the scale of credit funds and the supervision of credit risk. Supervision of the central bank is closely related to the credit business of commercial banks. First, the central bank can tighten or loosen monetary policy to indirectly control the scale of credit funds of commercial banks; secondly, improvement of the quality of regulatory personnel and the construction of regulatory infrastructure information can more effectively prevent the credit risk of commercial banks, such as, the construction of credit management system can break information barriers between banks, enterprises and individual users, further to decrease credit risk. Thirdly, studies from the perspective of macro Prudential policy (Hu, Li, 2020), show that the introduction of macro prudential policy on the basis of monetary policy is conducive to reducing economic fluctuations; when the financial market is faced with hit, macro prudential policy should be implemented together with monetary policy to reduce the fluctuation of the real estate price and credit growth rate ${ }^{[7]}$. Macro prudential policy can improve the foresight and efficiency of the central bank's monetary policy, and combination of the two policies can improve the efficiency of the central bank's supervision on commercial banks' credit business.

The above three views demonstrate the relationship between the supervision of the central bank and the credit business of commercial banks. After comparing the research papers at home and abroad, it is proved that the above-mentioned scholars have distinct views, laying a good foundation for the study on the central bank's credit supervision of commercial banks. In addition, because this study is carried out on the basis of post-epidemic era, academic research for which is at a relatively blank stage, so this paper can further fill in the research results of the central bank supervision, this paper explores the solutions to the loopholes with central bank supervision to reduce artificial capital drainage, and promote the stable development of China's economy which will provide theoretical reference for the credit supervision of central bank.

\section{ANALYSIS ON THE CURRENT SITUATION AND PROBLEMS OF CENTRAL BANK'S SUPERVISION ON CREDIT BUSINESS -- TAKING PING AN BANK AS AN EXAMPLE}

\section{A. Current situation of the central bank's supervision on commercial banks' credit}

Since the establishment of CBRC in 2003, the function of central bank in supervising commercial banks has been assigned to CBRC. The central bank 's regulation of commercial banks concentrates on monetary policy making and implementing, the function of macro prudence and the construction of credit reference system. Due to the differences in the credit business model among different commercial banks, considering that Ping An Bank is a commercial bank listed in A-share, with large scale and guaranteed information disclosure and the credit and financial data of Ping An Bank are relatively detailed, therefore Ping An Bank is taken as an example so as to enhance the depth of this research and make the research results more convincing.

Generally, enterprises or individuals apply for loans from commercial banks by way of operating property mortgage or fixed assets, as shown in figure 1 and figure 2. When applying for loans from Ping A Bank, the borrower first needs to provide relevant information, including personal asset certificates and evaluation reports. Then Ping An Bank shall carry out due diligence on the information of the borrower, aiming at making sure whether the borrower has the ability of repayment, in case that the borrower is unable or does not want to repay the loan, it easily leads to the rise of the non-performing asset ratio of the commercial bank, which may result into the liquidity risk of the commercial bank. While the credit reference center of the central bank can effectively help commercial banks collect information about borrower, which is the central bank's supervision on the loan process of commercial banks, and has the supporting function of judgment on borrower's ability to repay.

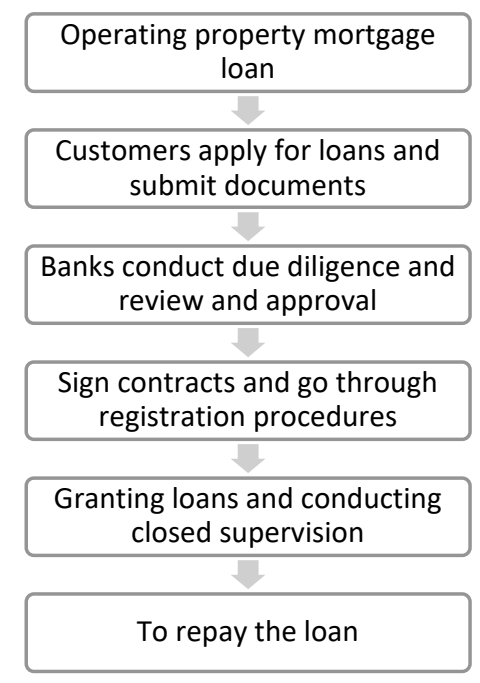

Figure 1. Operating property mortgage 


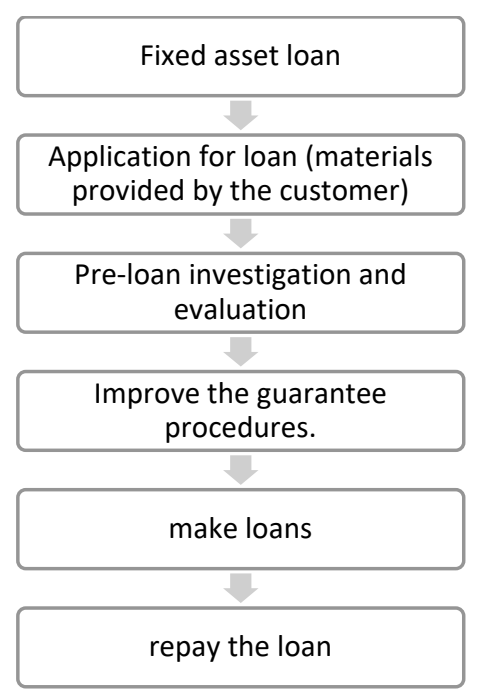

Figure 2. Fixed assets

The central bank can also conduct its credit supervision on commercial banks through money supply. As a bank's bank, the central bank realizes its direct effects on the amount of money circulation and the total scale of social credit by putting basic money into commercial banks, which is the basis of social money supply. Regulating money supply through monetary policy, such as opening market business, analyzing the current economic situation to determine whether to put liquidity into commercial banks; adjusting the deposit reserve ratio, indirectly guiding the loan interest rate of commercial banks; as well as other means, all are mainly aimed at controlling the scale of social credit to prevent financial risks. IN view of the economic situation under the epidemic, China's GDP fell by $10 \%$ month-on-month in the first quarter. To stimulate China's economy, the central bank adopted expansionary monetary policy, that is to stimulate the total social demand by increasing the money supply. In this case, the loan interest rate of commercial banks is generally low, and the central bank can control the quantity of money supply to realize the credit supervision of commercial banks.

In the post-epidemic era, the central bank has released a large amount of money liquidity with the purpose of stimulating the real economy. However, the loose monetary environment may lead to systemic credit risk and low economic stimulation efficiency. It may happen because of two problems existing in the central bank's credit supervision of commercial banks, i.e. the collection and processing of data and the implementation of monetary policy.

\section{B. Problem analysis on the supervision of commercial banks' credit business by the central bank}

1) Insufficient effectiveness of information collection

The credit management center of the central bank manages personal credit report and enterprise credit report, both of which can be used as the information query and collection of commercial bank's borrowers. The personal report covers six parts, i.e. the Ministry of public security's identity data verification results, personal basic data, bank credit transaction data, non-bank credit data, personal statement and objection marking and historical data inquiry. Enterprise credit report contains four parts, i.e. basic data, credit data, public data and statement data. The above data is mainly used for credit approval and post-loan management of commercial banks, reflecting whether the individual or enterprise has the risk of default or the ability to repay. Therefore, currently, user credit report of the central bank is only used to assists the commercial bank in a preliminary judgment on the applicant, that is to audit the applicant's credit to judge whether there is default risk, but it lacks more effective data to understand the asset status of users, and it is impossible to judge whether the loans are invested in the real estate or stock market. For example, during the COVID-19 epidemic, some investors buy a shell company with some funds, then making use of the central bank's preferential loan policy to apply for loans, and invest the loan funds at a lower interest rate in property market. Loan funds did not flow into the real economy, which may lead to asset bubbles. Therefore, the information of users' assets and the flow of loan funds are particularly important in the allocation of social capital.

According to the study by scholars Zhang, Liang and Zhu (2018), it is found that the rise of money supply provided sufficient liquidity, which effectively promoted the rise of housing prices in first tier cities ${ }^{[18]}$. In a loose monetary situation, house prices easily go up. As a macro-economic regulator, the central bank lacks the data such as the flow of the loan funds, whether the loan is used for investment, etc. so that it cannot effectively control the stability of house prices. Therefore, the central bank's credit supervision of commercial banks should concentrate on the review of the borrower's information, including the use of loan capital. While, to ensure sufficient liquidity and avoid the occurrence of non-performing loans, commercial banks should attach great importance to the audit of borrower's ability to repay. In order to effectively stimulate the development of the real economy rather than the virtual economy, the central bank needs to strengthen the effectiveness of information audit, including the information of the real estate or other assets owned by the borrower, and collecting the information about whether the loan enterprise has real business.

2) Insufficient guidance for value oriented monetary policy

The limitation of monetary policy is that the central bank cannot judge the scale of social needs. With the guidance of commercial banks' credit, a loose monetary environment will lead to excessive capital to flow into the society, easily inducing asset bubbles or the situation that enterprises that do not need to operate loans apply for loans and then invest in speculative commodities. If the central bank does not control the scale of the money supply, it will aggravate market imbalances.

The central bank's credit supervision on commercial banks includes indirectly guiding the total credit number of commercial banks by monetary policy, so as to control the amount of social funds in the market. In view of different economic situation, different monetary policies are adopted to stabilize China's economic development. 
Tightening monetary policy in the period of inflation is conducive to the decline of inflation; in the period of economic recession, loose monetary policy is conducive to stimulating the economy, but the effect of the latter is not significant. According to the study by scholars (Guo, Lu, Guo, Yan, Meng, 2009), in the third and fourth quarters of 2008, the impact of money supply on GDP is weaker than that of normal economic situation [20]. According to the data, in April and May of 2020, China's M2 increased by $11.1 \%$ year-on-year, and RMB loans increased by 1.48 trillion [35]. China's GDP is 25011 billion yuan in the second quarter, an increase of $3.2 \%$ on a year-on-year basis, and a decrease of $6.8 \%$ in the first quarter ${ }^{[36]}$.

The above data indicate that during the economic downturn, a large amount of funds have not entered the real economy, and the monetary policy of the central bank has not worked well in stimulating the economy to the greatest extent. Because a series of policies launched by the central bank aim to support the small and medium-sized enterprises and benefit the people's livelihood, resulting in a large amount of liquidity release. Therefore, loans from commercial banks flow to the assets such as gold and real estate market, resulting that the growth rate of GDP does not match the growth rate of money supply. Therefore, it is concluded that the scale of social capital demand is what the central bank's credit supervision of commercial banks should attach great importance to. In view of the loopholes in credit supervision, this paper puts forward two exploratory proposals, i.e. combination of big data technology with central bank supervision and introduction of active monetary policy into the index of real estate price coefficient.

\section{EXPLORATORY PROPOSALS}

\section{A. Strengthen information processing with the use of big data}

The enhancement of information collection and processing technology is for the purpose of avoiding disordered capital flow caused by information asymmetry. Scholars (Yang, 2017) hold a view that big data technology can further enrich data sources, increase analysis methods, expand sharing channels, making new changes to the central bank's financial decision analysis, prevention and resolution of financial risks, and maintenance of national financial stability ${ }^{[22]}$. With the use of the literature research, collation and analysis on corresponding literature come into a conclusion that the information processing of big data, the problem of insufficient effectiveness with central bank information collection can be effectively solved, the efficiency of information processing can be improved, which can reduce information barriers in the central bank's credit supervision of commercial banks.

With the development of big data in China, the information processing and information collection technology in all walks of life will leaps forward. In view of prospect of the financial industry, "big data + finance" will optimize data processing technology of the financial industry. The combination of big data technology and the supervision of the central bank can improve the central bank's ability to review and understand the borrower's information, and strengthen the supervision of commercial banks in the credit process, improve the efficiency of information collection. Meanwhile, it also develops new theoretical basis for following research, deepens the understanding of the importance of central bank's supervision on the stable development of financial market, and updates the significance of central bank's supervision on commercial bank's credit business. However, the limitation of this study is that the central bank lacks specific big data application, so that it is impossible to make analysis on the basis of practical application. If this limitation can be broken through, then the information barrier can be broken and the efficiency and accuracy of information processing can be improved; as for the study in this paper, the paper will be more practical with higher theoretical value and actual value.

\section{B. Introduce positive monetary policy into the index of real estate price coefficient}

The limitations of monetary policy lead to the central bank's failure to maximize the efficiency of monetary policy. Exploratory research with the use of qualitative research, draws a conclusion that, to include real estate price into the reference index of monetary policy, it can strengthen the efficiency of central bank's credit supervision of commercial banks. Positive monetary policy is likely to produce surplus liquidity in the market, resulting in asset bubbles. As a hedge asset, the real estate, in good or depressed economic situation, the price of the real estate will not have a big drop, especially in the first and second tier cities, and the price is even rising So, investors usually invest in the property market when they hold stable funds or the economic environment is loose. If the real estate price coefficient is included as the reference index of monetary policy, in the situation of loose credit, it can effectively prevent investors from investing in the real estate market with loans, and better carry out the instruction of "house for live rather than investment". It supervises the credit business of commercial banks from the perspective of money supply, leading funds to the entity field.

\section{Conclusion And Prospect}

In post-epidemic era, the global economy will develop a new pattern. As the most important transaction subject in the financial market and the supervisor of commercial banks, it is extremely important for the central bank to correctly guide the flow of credit funds of commercial banks for the steady development of China's financial industry. The central bank's credit supervision of commercial banks determines the scale of social credit, the quantity of money supply. It regulates the balance of social supply and demand at money supply side.

In view of the problems with information collection and processing and the limitations of monetary policy in the supervision of the central bank, it can be solved by strengthening the information collection and processing with combination with big data technology, and including 
the real estate price into the reference index of monetary policy. This study can effectively enhance the efficiency of central bank's supervision, and guide social funds to flow to the real economy from the perspective of money supply and information audit, in addition, there are some limitations in this study, there is no specific application and modeling analysis. This paper makes a theoretical hypothesis. If the central bank further studies the credit supervision of commercial banks, in the further study of central bank's supervision on commercial bank credit, specific application and modeling analysis can be adopted for verification, further improving the applicability of the study of this paper in practice, strengthening the representativeness of the paper, enabling it to have great theoretical and practical value.

\section{ACKNOWLEDGMENT}

First of all, I would like to express my gratitude to all those who helped me during the writing of this thesis. I gratefully acknowledge the help of my supervisor, FANG Huan, who has offered me valuable suggestions in the academic studies. In the preparation of this thesis, he has spent much time correcting each draft and provided me with inspiring advice. Without his patient instruction, insightful criticism and expert guidance, the completion of this thesis would not have been possible.

Second, I also owe a special debt of gratitude to author and professor of references, from whose devoted enlightening point of view I have benefited a lot and academically prepared for the thesis.

Finally, I am greatly indebted to Mrs. Zhang, who is my finance tutor and helped me to overcome the shortcomings of the theory and methods in the course of the thesis. I would like to express my deep gratitude to her.

\section{REFERENCE}

1. Cao S.G.,SHI C.W.,Zhang G.Y.,Coordinated development of financial supervision and construction of supervisory team of central Bank [J]. Hebei Finance,2014(9):53-55.

2. Zhu M.Y.,Macroprudential Regulation and The Implications of China's Central Bank regulation [J]. Financial Economy: the second half of the Month,2010(8):108-109.

3. Yin J.Z., Thinking on strengthening the Macro-prudential Management Function of central bank. Research on Financial Development,2011(9):35-39.

4. Wei W.,Jiang H.,Pang S.L.,Empirical Analysis of Monetary Policy Supervision policy and Bank Credit Behavior based on China's Banking Industry $(2002,2012)$. International Financial Studies, 2016(5):48-60.

5. Zhang X.C.,A study on interest rate liberalization and commercial bank development. Guizhou Rural Finance,2004(6):28-31.

6. Cui Y.B., The ways of supervising and managing the credit risk of commercial Banks. Sme management and technology,2020(2):11-12.

7. Hu C.C.,Li Y.,The selection of monetary policy tools under the macroprudential framework. Journal of Anhui Normal University: Humanities and Social Sciences,2020,48(1):138-146.

8. Bernanke B.S.,Blinder A.S. Credit, Money and Aggregate Demand[J]. American Economic Review, 1988 (2) : 435-439

9. Ji C.C,On the Enlightenment of the Financial Crisis to the Credit management of commercial Banks. The Chinese market,2011(1):35-35

10. Lu Z.W.,CHEN H.,Financial regulatory policies to help prevent and control the epidemic $[\mathrm{J}]$. Economic perspective,2020(3):10-12.

11. Chen P.,Coordination of Central and Local Financial Supervision: Experience Review and Prospect. Southwest of financial,2020(4):22-33.

12. Xu Z.,Zhang X.C.,Zhou C.W.,Housing price inflation and monetary policy based on Chinese data. Financial research,2012(6):1-12.

13. Deng A.B.,Transformation of credit management of commercial Banks. China's financial,2016(23):34-35.

14. Cheng S.H.,Huang Z.G.,Lin C.Y.,Xu Y.L.,A Study on the Influence of targeted RRR Reduction policy on the credit behavior of commercial Banks. China's Economic problems,2019(1):14-26.

15. Li T.F.,Current problems and improvement paths of small and micro credit business. Shanghai's financial, 2019(10):82-87.

16. Chen H.,From the perspective of bank non-performing loans, the fraud in corporate financial statements is based on the perspective of bank credit business audit. Photocopying newspaper materials: Guide to Finance and Accounting,2017(4):77-80.

17. Liu H.J.,Research on the Internal control of sme credit Business take HSBC (China) for example. Finance and Accounting Newsletter: Zhong,2015(11):113-115.

18. Zhang Q.Y.,Liang R.B.,Zhu F.,Does monetary policy exacerbate urban housing inequality? Statistical study,2018,35(5):75-87.

19. Xiao J.W.,Li Y.,Monetary policy responses to the financial crisis. Science of finance and economics,2009(7):1-9.

20. Guo J.E.,Lv C.,Guo G.T.,Yan W.J.,Meng L.,Evaluation on the effect of Monetary policy implementation in Response to American financial crisis in China. Journal of $\mathrm{Xi}$ 'an Jiaotong University: Social Science Edition,2009,29(6):1-4.

21. Liu X.X.,Ge Y.,Dong K.,Stock price fluctuation housing consumption and monetary policy choice. Journal of $\mathrm{Xi}$ 'an University of Finance and Economics,2020,33(2):40-49.

22. Yang H., The construction and Application prospect of big data of central bank. Electronic finance,2017(9):11-13.

23. Li Y.J.,Build a capital firewall between the real estate market and the real estate market based on LPR,2019(28):34-37.

24. Wang N.,Why monetary policy often fails Is based on modern monetary theory's criticism of mainstream monetary theory. Academic research,2020(2):96-101.

25. Tan C.Z.,Liang C.Y.,Geng X.X.,The influence of monetary policy on liquidity risk is based on the perspective of bank credit behavior. Research on Financial Regulation,2020(1):84-96.

26. Wei X.,Analysis of the influence of China's macroprudential Policy on the transmission mechanism of monetary policy. China's prices, 2020(1):28-31

27. Ma L.,Fan W.,Where did the liquidity released by central Banks go? -- Empirical test based on micro-level data. Contemporary Economic Science, 2019,41(3):39-48.

28. Tang K.,Research on the influence of LPR reform on central bank policy regulation and commercial bank operation. new finance, 2020(4):44-49.

29. Chen Y.Y.,Research on the current situation and Countermeasures of Real estate credit supervision in China. The open herald,2010(5):99-102.

30. Zhang L.,Research on new Countermeasures of Credit risk management of Commercial Banks in China in the post-financial crisis era. Strait technology and industry,2017(8):44-45.

31. Yu L.,LI C.B.,Zhao P.,The causes and consequences of the financial turmoil on Wall Street. Contemporary Economic Science,2009(2):1-6. Exhibition, expanding Domestic Demand; Measures will be taken to maintain steady and sound development of the real estate market。

32. Eda Gülşen,Erdal Özmen. Monetary policy trilemma, inflation targeting and global financial crisis[J]. International Journal of Finance \& Economics, 2020,25(2).

33. National Bureau of Statistics. In January and April 2020, the profits of industrial enterprises above designated size in China 
declined

27.4\%[EB/OL].http://www.stats.gov.cn/tjsj/zxfb/202005/t202005 27 1748217.html

34. the People's Bank of China.China's Monetary Policy Implementation Report for the First Quarter of 2020 [EB/OL].http://www.pbc.gov.cn/zhengcehuobisi/125207/125227/ 125957/4021036/4021012/index.html

35. National Bureau of Statistics. Statistical Data Report of Social Financing Scale stock in May 2020
[EB/OL].http://www.pbc.gov.cn/diaochatongiisi/116219/116225/ 4037642/index.html

36. NBS. Money supply for the first quarter of 2020 [EB/OL].http://data.stats.gov.cn/easyquery.htm?cn=A01

37. National Bureau of Statistics zhao Tonglu: Economic growth from negative to positive overall economic recovery [EB/OL].http://www.stats.gov.cn/tjsj/sjjd/202007/t20200717 17 76624.html 